\title{
Surface reconstruction establishing Mott-Schottky heterojunction and built-in space-charging effect accelerating oxygen evolution reaction
}

\author{
Yao Kang ${ }^{1,}$, Shuo Wang ${ }^{1,}$, Kwan San $\mathrm{Hui}^{2}(\bowtie)$, Shuxing Wu${ }^{3}$, Duc Anh Dinh ${ }^{4}, \mathrm{Xi} \mathrm{Fan}^{5}$, Feng Bin ${ }^{6}$, Fuming Chen ${ }^{7}$ \\ Jianxin Geng $^{8}$, Weng-Chon (Max) Cheong ${ }^{9}(\bowtie)$, and Kwun Nam Hui ${ }^{1}(\bowtie)$ \\ ${ }^{1}$ Joint Key Laboratory of the Ministry of Education, Institute of Applied Physics and Materials Engineering, University of Macau, Taipa, Macau \\ 999078, China \\ ${ }^{2}$ Engineering, Faculty of Science, University of East Anglia, Norwich NR4 7TJ, UK \\ ${ }^{3}$ School of Chemical Engineering and Light Industry, Guangdong University of Technology, Guangzhou 510006, China \\ ${ }^{4}$ NTT hi-tech institute, Nguyen Tat Thanh university, Ho Chi Minh city 700000, Vietnam \\ ${ }^{5}$ Ningbo Institute of Materials Technology, Engineering, Chinese Academy of Sciences, Ningbo 315201, China \\ ${ }^{6}$ State Key Laboratory of High-Temperature Gas Dynamics, Institute of Mechanics, Chinese Academy of Science, Beijing 100190, China \\ ${ }^{7}$ State Key Laboratory of Optic Information Physics and Technologies, School of Physics and Telecommunication Engineering, South China Normal \\ University, Guangzhou 510006, China \\ ${ }^{8}$ State Key Laboratory of Organic-Inorganic Composites, Beijing University of Chemical Technology, 15 North Third Ring East Road, Chaoyang \\ District, Beijing 100029, China \\ ${ }^{9}$ Department of Physics and Chemistry, Faculty of Science and Technology, University of Macau, Taipa, Macao 999078, China \\ ${ }^{\S}$ Yao Kang and Shuo Wang contributed equally to this work.
}

(c) The Author(s) 2021

Received: 7 September 2021 / Revised: 27 September 2021 / Accepted: 29 September 2021

\section{ABSTRACT}

Structural reconstruction of nanomaterials offers a fantastic way to regulate the electronic structure of active sites and promote their catalytic activities. However, how to properly facilitate surface reconstruction to overcome large overpotential that stimulate the surface reconstruction has remained elusive. Herein, we adopt a facile approach to activate surface reconstruction on $\mathrm{Ni}(\mathrm{OH})_{2}$ by incorporating $\mathrm{F}$ anions to achieve electro-derived structural oxidation process and further boost its oxygen evolution reaction (OER) activity. Ex situ Raman and X-ray photoemission spectroscopy studies indicate that $F$ ions incorporation facilitated surface reconstruction and promotes the original $\mathrm{Ni}(\mathrm{OH})_{2}$ transformed into a mesoporous and amorphous $\mathrm{F}-\mathrm{NiOOH}$ layer during the electrochemical process. Density functional theory (DFT) calculation reveals that this self-reconstructed NiOOH induces a space-charge effect on the $\mathrm{p}-\mathrm{n}$ junction interface, which not only promotes the absorption of intermediates species $\left({ }^{*} \mathrm{OH},{ }^{*} \mathrm{O}\right.$, and $\left.{ }^{*} \mathrm{OOH}\right)$ and charge-transfer process during catalysis, but also leads to a strong interaction of the $p-n$ junction interface to stabilize the materials. This work opens up a new possibility to regulate the electronic structure of active sites and promote their catalytic activities.

\section{KEYWORDS}

F anions, dynamic migration, nickel hydroxides, surface reconstruction, oxygen evolution reaction (OER)

\section{Introduction}

Electrocatalytic water splitting for hydrogen and oxygen generation offers an appealing road for obtaining renewable energies [1-5]. However, oxygen evolution reaction (OER) within the electrocatalytic water splitting process is a kinetically slow and efficiency-limiting reaction due to the four-electron redox steps, which often involves a high overpotential to dissociate $\mathrm{O}-\mathrm{H}$ bond and to form $\mathrm{O}=\mathrm{O}$ bond [6-9]. Currently, precious metal oxides, such as Ir, and Ru oxides are highly efficient OER electrocatalysts, but they suffer from relative scarcity and high-cost [10-13]. In this respect, well-engineered catalysts prepared using earth-abundant elements, such as $\mathrm{Fe}, \mathrm{Co}$, and $\mathrm{Ni}$ (and their derivatives) may offer affordable substitutes [14-19].
A fact that cannot be neglected is that most active sites on the surface of catalysts would undergo structural reconstruction due to the electro-derived structural oxidation process [20-22]. Transition metal oxyhydroxides $(\mathrm{MOOH}$, where $\mathrm{M}=\mathrm{Fe}$, Co or $\mathrm{Ni}$ ) are well-recognized as the real catalytically active species generated from irreversible surface reconstruction on different types of oxygen-evolving materials [23-25]. In particular, Ni-based samples have garnered high potential in surface reconstruction due to $\mathrm{Ni}-\mathrm{O}$ bond breaking under high oxidation potential, showing their encouraging water oxidation potential [26-28]. However, how to properly facilitate this surface reconstruction to overcome large overpotential that stimulates the surface reconstruction due to the strong $\mathrm{Ni}-\mathrm{O}$ bond has remained

Address correspondence to Kwan San Hui, k.hui@uea.ac.uk; Weng-Chon (Max) Cheong, maxcheong@um.edu.mo; Kwun Nam Hui, bizhui@um.edu.mo 
elusive, not to mention the unveiling of such mechanism. Furthermore, surface reconstruction should be precisely controlled to avoid compromising all the bulk of catalysts, which serves as a template for creating a highly active surface. Thus, it is highly desirable to develop strategies for activating and terminating surface reconstruction. Recent studies have reported that $\mathrm{F}$ anion with the strongest electronegativity (3.98) compared to other nonmetal elements, due to its similar ionic radius to oxygen ions ( $\mathrm{F}$ : $0.131 \mathrm{~nm}$ and O: $0.138 \mathrm{~nm}$ ), can facilitate the activation of catalytic active species in metal hydroxide-based catalysts [29,30]. Most importantly, it tends to form weaker metal-F bonds than that of other metal-anion bonds by virtue of structural features of $\mathrm{F}$ anions, which is easier to bring stronger ionicity for realizing surface reconstruction of catalytic active species $[29,30]$. However, the study of this completely-new structural reconstruction strategy to activate OER active species in metal hydroxide-based material remains a blank.

In this work, we adopt a facile approach to promote surface reconstruction on $\mathrm{Ni}(\mathrm{OH})_{2}$ by incorporating $\mathrm{F}$ anions $\left(\mathrm{F}-\mathrm{Ni}(\mathrm{OH})_{2}\right)$ to regulate the electronic structure of active sites and thus to promote the OER activities. The F anion with the strongest electronegativity trends on forming weak $\mathrm{Ni}-\mathrm{F}$ bonds and achieves stronger ionicity than $\mathrm{Ni}-\mathrm{O}$ bonds, which is in favor of surface reconstruction of catalytic active species. During the electrochemical process, large amounts of $\mathrm{F}$ anion were leached and the original surface layer was transformed into a mesoporous and amorphous F-NiOOH layer. This self-reconstructed $\mathrm{NiOOH}$ promotes a space-charge effect on the $\mathrm{p}-\mathrm{n}$ junction interface (F-NiOOH/F-Ni(OH $)_{2}$ ), which is able to not only change the electron densities of atoms around the interfaces but also accelerate the absorption of targeted ions and the charge-transfer process during catalysis. This work opens up a new possibility to regulate the electronic structure of active sites and promote their catalytic activities.

\section{Experimental}

\subsection{Preparation of $\mathrm{F}-\mathrm{Ni}(\mathrm{OH})_{2}$}

Nickel form $(2 \mathrm{~cm} \times 3 \mathrm{~cm})$ was firstly washed by hydrochloric acid, ethanol, and deionized (DI) water. $\mathrm{F}-\mathrm{Ni}(\mathrm{OH})_{2}$ nanowires growing on nickel foam were firstly synthesized by a hydrothermal method. Specifically, $148 \mathrm{mg} \mathrm{NH} \mathrm{NH}_{4} \mathrm{~F} 60 \mathrm{mg}$ urea, and $1.64 \mathrm{~g} \mathrm{Ni}\left(\mathrm{NO}_{3}\right)_{2}$ were dissolved in $40 \mathrm{~mL}$ DI water and mixed under vigorous stirring. Then, the mixed solution was transferred to $50 \mathrm{~mL}$ stainless steel Teflon-lined autoclave and maintained at $120{ }^{\circ} \mathrm{C}$ for $6 \mathrm{~h}$. The $\mathrm{F}-\mathrm{Ni}(\mathrm{OH})_{2}$ nanowires growing on nickel foam were obtained after cooled down naturally to room temperature, final washed by ethanol and DI water.

\subsection{Preparation of $\mathrm{F}-\mathrm{Ni}(\mathrm{OH})_{2}$-SR catalysts}

To obtain the $\mathrm{F}-\mathrm{Ni}(\mathrm{OH})_{2}-\mathrm{SR}$ catalysts, the $\mathrm{F}-\mathrm{Ni}(\mathrm{OH})_{2}$ nanowires growing on nickel foam were treated by performing cyclic voltammetry $(\mathrm{CV})$ treatment $(50,100,150,200,250$ cycles, named F-Ni(OH $)_{2}$-SR-50, F-Ni(OH $)_{2}$-SR-100, F-Ni(OH $)_{2}$-SR-150, $\mathrm{F}-\mathrm{Ni}(\mathrm{OH})_{2}-\mathrm{SR}-200$, and $\left.\mathrm{F}-\mathrm{Ni}(\mathrm{OH})_{2}-\mathrm{SR}-250\right)$. The scan rate for $\mathrm{CV}$ was kept at $50 \mathrm{mV} \cdot \mathrm{s}^{-1}$.

\subsection{Characterizations}

The crystal structure of materials was tested using a Rigaku Smartlab 9000W X-ray diffractometer with a scan rate of $10^{\circ} \cdot \mathrm{s}^{-1}$. Field emission scanning electron microscope (FESEM) (JEOL JSM-7500F) were performed to obtain the morphologies and elemental composition of the synthesized samples. Transmission electron microscopy (TEM) and selected area electron diffraction (SAED) were carried out on a JEOL JEM-2100 microscope. Raman spectra were obtained with a $320 \mathrm{~nm}$ laser by using a RENISHAW system. X-ray photoelectron spectroscopic (XPS) studies were performed using a Thermo ESCALAB 250 instrument. The thickness of samples was determined by atomic force microscopy (AFM) (Bruker MM8).

\subsection{Electrochemical measurements}

Electrochemical measurements were carried out in a three-electrode system on a CHI 760E electrochemical workstation (Shanghai Chenhua, China) in $1 \mathrm{M} \mathrm{KOH}$ electrolyte. The $\mathrm{Ag} / \mathrm{AgCl}$ (saturated $\mathrm{KCl}$ solution) and $\mathrm{Pt}$ foil were used as reference and counter electrodes, respectively. Linear sweep voltammetry (LSV) was measured from $1.0-1.8 \mathrm{~V}$ at the scan rate of $10 \mathrm{mV} \cdot \mathrm{s}^{-1}$. The impedance spectra of materials were performed in the three-electrode setup over the frequency range from $1 \mathrm{MHz}$ to $0.1 \mathrm{~Hz}$ in $1 \mathrm{M} \mathrm{KOH}$. All the LSV data in this work were corrected by eliminating $i R$ drop with respect to the ohmic resistance of solution.

\subsection{Computational methods}

All the calculations were performed based on the density function theory (DFT) methods implemented in the Vienna $a b$ initio simulation package (VASP) (5.4). The generalized gradient approximation was used to estimate exchange-correlation interaction in the scheme of the Perdew-Burke-Ernzerhof functional. The effect of core electrons on the density of valence electrons was described using the projector augmented wave method. The kinetic energy cutoff for the plane waves was set to $450 \mathrm{eV}$ for all the calculations in the $3 \times 3 \times 1 \mathrm{Ni}(\mathrm{OH})_{2}$ super cells. The convergence tolerance of energy and force on each atom during structure relaxation were less than $10^{-4} \mathrm{eV}$ and $0.02 \mathrm{eV} \cdot \AA^{-1}$, respectively. A set of Monkhorst-Pack mesh K points of $3 \times 3 \times 1$ optimization and electronic structural calculations. A vacuum distance of $20 \AA$ was set for $\mathrm{Ni}(\mathrm{OH})_{2}$ to ensure sufficient vacuum and avoid interactions between two periods. The thermal and zero-point energy (ZPE) corrections of different $\mathrm{C}$ intermediates adsorbed onto $\mathrm{Ni}(\mathrm{OH})_{2}$ were further calculated at the $\Gamma$ point. Dispersion-corrected DFT scheme of Grimme was used to describe the van der Waals interactions in the systems.

\section{Results and discussion}

\subsection{Crystal structure characterization}

$\mathrm{F}-\mathrm{Ni}(\mathrm{OH})_{2}$ nanowires growing on nickel foam were firstly synthesized by a hydrothermal method (Scheme 1) [31]. It can be seen from the real photos that $\mathrm{F}-\mathrm{Ni}(\mathrm{OH})_{2}$ grows uniformly on the surface of the nickel foam (Fig. S1 in the Electronic Supplementary Material (ESM)). X-ray diffraction (XRD) pattern in Fig. S2 in the ESM shows four main peaks at $19.3^{\circ}, 33.5^{\circ}, 38.9^{\circ}$, and $59.9^{\circ}$, which are indexed to the (001), (100), (011), and (110) planes of $\mathrm{Ni}(\mathrm{OH})_{2}$ (JCPDF\#73-1520), respectively [27]. The scanning electron microscopy (SEM) image shows that the original $\mathrm{F}-\mathrm{Ni}(\mathrm{OH})_{2}$ has a nanowire morphology with a diameter of approximately $50 \mathrm{~nm}$ and a smooth surface (Fig. S3 in the ESM). TEM images further identify the nanowire structure of $\mathrm{F}-\mathrm{Ni}(\mathrm{OH})_{2}$, as shown in Fig. S4 in the ESM. High-resolution TEM (HRTEM) in Fig. S5 in the ESM shows a clear lattice strain with a $d$-space of $0.233 \mathrm{~nm}$, which corresponds to the (011) planes of $\mathrm{Ni}(\mathrm{OH})_{2}$ [32]. The high-angle annular dark-field scan TEM (HAADF-STEM) images and energy-dispersive $\mathrm{X}$-ray (EDX) mapping indicated that $\mathrm{F}, \mathrm{Ni}$, and $\mathrm{O}$ are homogeneously distributed in the whole materials (Fig. S6 in the ESM). 


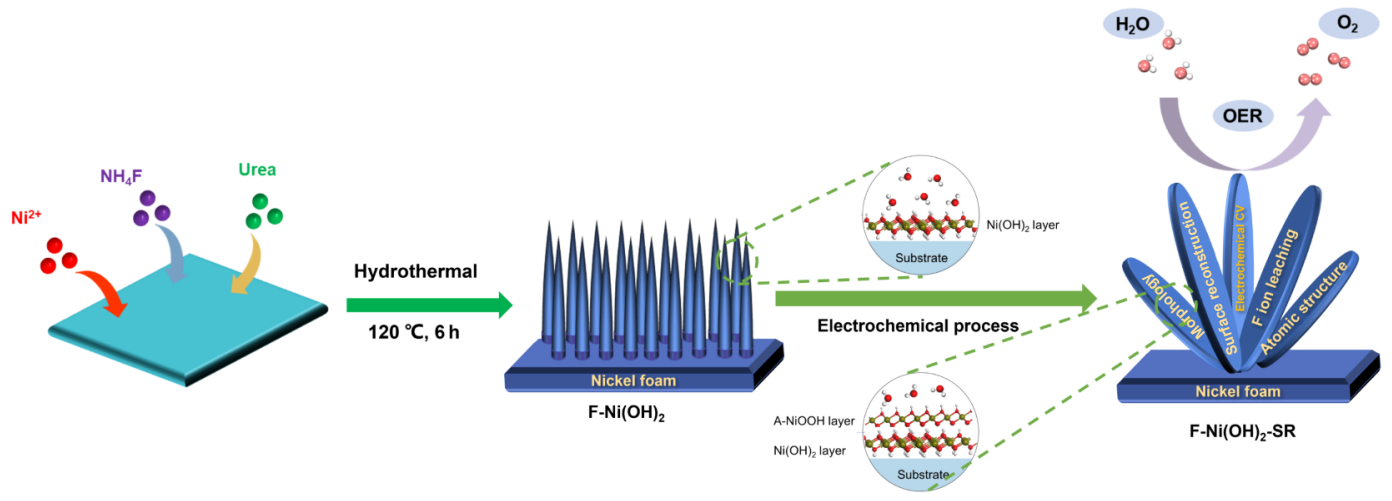

Scheme 1 Schematic illustration for the synthesis of materials.

\subsection{CV treatment promoting surface reconstruction}

To uncover the influence of $\mathrm{F}$ ions on the catalytic activity of material during the electrochemical process, $\mathrm{CV}$ was performed in a $1 \mathrm{M} \mathrm{KOH}$ solution. Figure 1(a) shows the CV curve of the $\mathrm{F}-\mathrm{Ni}(\mathrm{OH})_{2}$ from 1 to 10 cycles. It is shown that the area and position of the $\mathrm{Ni}$ oxidation peak were changed from $\mathrm{Ni}^{2+}$ to $\mathrm{Ni}^{3+}$ as increasing the $\mathrm{CV}$ number, which indicates the controllable chemical state and composition of the materials $[33,34]$. Specifically, the area of the $\mathrm{Ni}$ oxidation peak $\left(\mathrm{Ni}^{2+}\right.$ to $\left.\mathrm{Ni}^{3+}\right)$ gradually increases, and the onset potential shifts negatively due to a strong electron transfer, which suggests $\mathrm{Ni}(\mathrm{OH})_{2}$ is gradually transformed into $\mathrm{NiOOH}$ [35]. Besides, the position of the $\mathrm{Ni}$ oxidation peak slightly shifts positively, suggesting phase change from $\mathrm{Ni}(\mathrm{OH})_{2}$ to $\mathrm{NiOOH}$. Previous studies have demonstrated that the formation of $\mathrm{NiOOH}$ in the electrochemical process is a key step for improving electrochemical activity [36-40]. To verify the increased catalytic activity of $\mathrm{F}-\mathrm{Ni}(\mathrm{OH})_{2}$ after surface reconstruction, a series of LSV were performed in $1 \mathrm{M} \mathrm{KOH}$ solution after 50, 100, 150, 200, and 250 cycles CV treatment (Fig. 1(b)). Considerably, LSV curves show that the electrochemical activity is greatly improved with increasing the CV number and approximately stable at 200 cycles. In particular, the electrochemical activity is increased by 50 times at a voltage of 1.6 $\mathrm{V}$ compared to the original $\mathrm{F}-\mathrm{Ni}(\mathrm{OH})_{2}$. In addition, the position of the $\mathrm{Ni}$ oxidation peak slightly shifts positively from 0 to 150 cycles due to surface reconstruction, which corresponds to the $\mathrm{Ni}^{2+}$ to $\mathrm{Ni}^{3+}$. However, the oxidation peak is around at $1.45 \mathrm{~V}$ after 200 cycles, which is ascribed to the $\mathrm{Ni}^{3+}$ to $\mathrm{Ni}^{4+}$ due to surface reconstruction almost finished, as shown in Fig. 1(b).

To explore the behavior of $\mathrm{F}-\mathrm{Ni}(\mathrm{OH})_{2}$ before and after $\mathrm{CV}$ treatment and identify the origin of the increased activity, a series of material characterizations were performed. Figure 1(c) shows SEM image of $\mathrm{F}-\mathrm{Ni}(\mathrm{OH})_{2}$-SR-200, the morphology changed from a nanowire structure (Fig. S3 in the ESM) to a crosslinked nanosheet structure (Fig. 1(c)), indicating the surface reconstruction occurred during the electrochemical process. TEM image also shows the nanosheets morphology of $\mathrm{F}-\mathrm{Ni}(\mathrm{OH})_{2}-\mathrm{SR}-200$ (Fig. 1(d)), further indicating the surface reconstruction of (a)

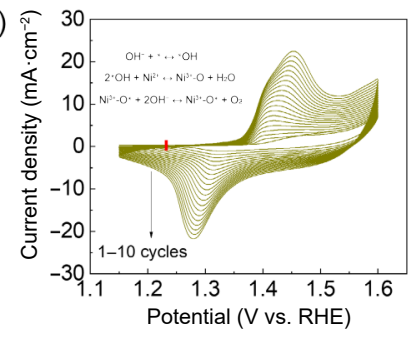

(d)

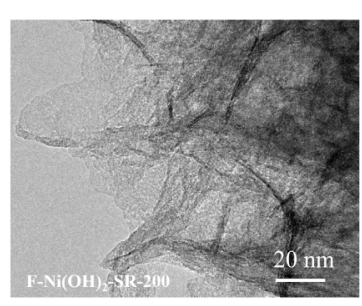

(g)

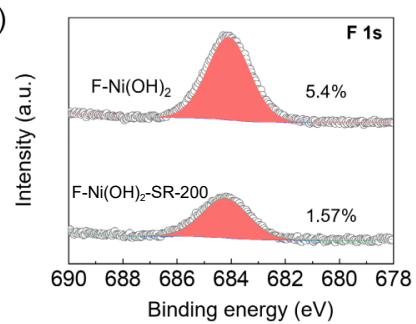

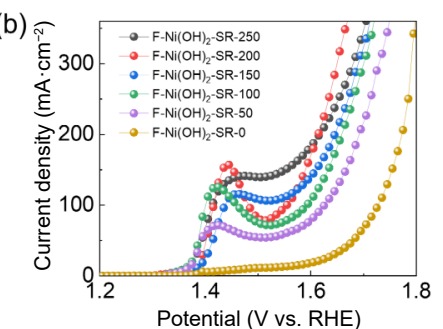

(c)

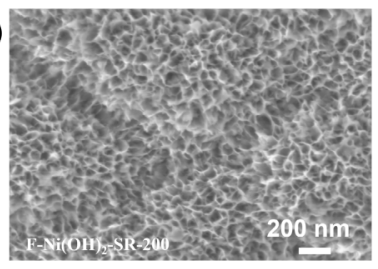

(e)
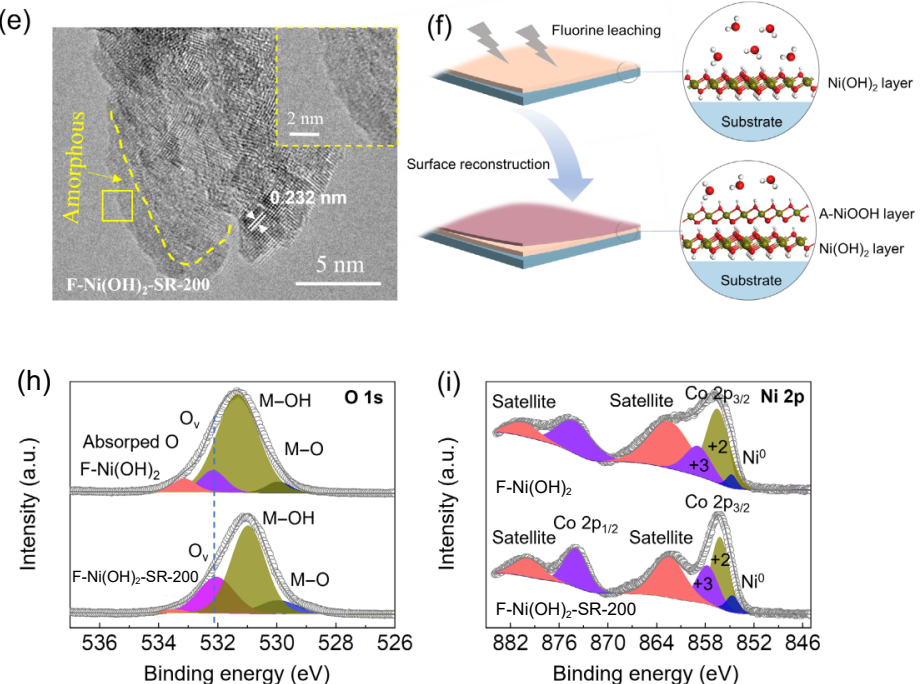

Figure 1 (a) CV curves of $\mathrm{F}-\mathrm{Ni}(\mathrm{OH})_{2}$ from 1 to 10 cycles. (b) LSV curves of F-Ni(OH) $)_{2}$-SR with 0, 50, 100, 150, 200, and 250 cycles. (c) SEM images of F-Ni(OH) after $200 \mathrm{CV}$ treatment. (d) TEM and (e) HRTEM images of F-Ni(OH) $)_{2}$ after $200 \mathrm{CV}$ treatment. (f) Illustration of surface reconstruction of materials. (g)-(i) XPS spectra of $\mathrm{F} 1 \mathrm{~s}, \mathrm{O} 1 \mathrm{~s}$, and $\mathrm{Ni} 2 \mathrm{p}$ before and after $200 \mathrm{CV}$ treatment, respectively. 
materials during the electrochemical process. This is because the $\mathrm{Ni}-\mathrm{OH}$ bond is broken and active species $\mathrm{NiOOH}$ is generated on the surface during the electrochemical process. In addition, due to the weak Ni-F bond, the leaching of $\mathrm{F}$ ions further accelerates this reconstruction and induces a phase change on the surface. The cross-linked nanosheets can increase the conductivity of the material and enhance the diffusion of intermediate products during the oxygen evolution process, thereby improving electrochemical activity $[41,42]$. Figure 1(e) shows the HRTEM images, a layer of the amorphous structure was formed on the surface after $\mathrm{CV}$ treatment, indicating that surface reconstruction occurred during the electrochemical process. EDX mapping was also used to explore the composition and composition of materials (Fig. S7 in the ESM). The images show that $\mathrm{Ni}, \mathrm{O}$, and $\mathrm{F}$ are uniformly distributed in the material structure, but the $\mathrm{F}$ content in $\mathrm{F}-\mathrm{Ni}(\mathrm{OH})_{2}-\mathrm{SR}-200$ is significantly reduced, indicating the the leaching of $\mathrm{F}$ ions during the electrochemical process. Figure $1(\mathrm{f})$ shows a schematic diagram of the electrochemical behavior of the material in the electrochemical process. The incorporation of $\mathrm{F}$ ion provides a weaker $\mathrm{Ni}-\mathrm{F}$ bond in the $\mathrm{Ni}(\mathrm{OH})_{2}$. The weak $\mathrm{Ni}-\mathrm{F}$ bonds easily break down under the continuous potential $(1.25-1.65 \mathrm{~V})$, which promotes unsaturated coordination of $\mathrm{Ni}$ atoms, thereby accelerating the surface reconstruction. Therefore, an amorphous layer structure was observed on the surface of materials, which forms a heterostructure and induces electronic structure reformation and space charging effect.

XPS spectrum was performed to further confirm the surface reconstruction of $\mathrm{F}-\mathrm{Ni}(\mathrm{OH})_{2}$, as shown in Figs. 1(g)-1(i). It is noted that both $\mathrm{F}-\mathrm{Ni}(\mathrm{OH})_{2}$ and $\mathrm{F}-\mathrm{Ni}(\mathrm{OH})_{2}-\mathrm{SR}-200$ show $\mathrm{Ni}, \mathrm{O}$, and $\mathrm{F}$ peaks, indicating no significant change in composition before and after $\mathrm{CV}$ treatment. The $\mathrm{F} 1 \mathrm{~s}$ spectrum shows the $\mathrm{Ni}-\mathrm{F}$ peak at $684.5 \mathrm{eV}$ (Fig. $1(\mathrm{~g}))[43,44]$. Compared with $\mathrm{F}-\mathrm{Ni}(\mathrm{OH})_{2}$, the $\mathrm{F}$ ion content in $\mathrm{F}-\mathrm{Ni}(\mathrm{OH})_{2}-\mathrm{SR}-200$ is reduced, which indicates the leaching of $\mathrm{F}$ ions during the electrochemical process. Figure 1(h) shows that $\mathrm{O} 1 \mathrm{~s}$ has four peaks, corresponding to $\mathrm{Ni}-\mathrm{O}, \mathrm{Ni}-\mathrm{OH}$, oxygen vacancies, and adsorbed oxygen $[45,46]$. The fitting results show that the $\mathrm{Ni}-\mathrm{OH}$ bond in $\mathrm{F}-\mathrm{Ni}(\mathrm{OH})_{2}-\mathrm{SR}-$ 200 decreases while the $\mathrm{Ni}-\mathrm{O}$ bond increases, suggesting the formation of $\mathrm{NiOOH}$ phase after surface reconstruction. In addition, the percentage of oxygen vacancy also increased as indicated by the increase of $\mathrm{O}_{2}$ peak at $531.2 \mathrm{eV}$, revealing surface reconstruction promotes the generation of defects, which further accelerates the behavior of oxygen precipitation. The $\mathrm{Ni} 2 \mathrm{p}$ spectrum in Fig. 2(i) shows that the chemical state of $\mathrm{Ni}$ has changed from $\mathrm{Ni}^{2+}$ to $\mathrm{Ni}^{3+}$. After $\mathrm{CV}$ treatment, the content of $\mathrm{Ni}^{3+}$ increases, while the content of $\mathrm{Ni}^{2+}$ decreases, indicating that a high chemical state substance $\mathrm{NiOOH}$ is produced [47].

\subsection{OER catalytic activity}

The OER catalytic activity of as-obtained F-Ni(OH $)_{2}$-SR-200, $\mathrm{F}-\mathrm{Ni}(\mathrm{OH})_{2}, \mathrm{Ni}(\mathrm{OH})_{2}-\mathrm{SR}-200, \mathrm{Ni}(\mathrm{OH})_{2}$, and $\mathrm{RuO}_{2}$ was evaluated in $\mathrm{N}_{2}$-saturated $1 \mathrm{M} \mathrm{KOH}$ solution at the scan rate of $10 \mathrm{mV} \cdot \mathrm{s}^{-1}$. Impressively, LSV curves in Fig. 2(a) show that F-Ni(OH) ${ }_{2}$-SR-200 exhibits the best electrocatalytic performance among all samples, which only needs 287 and $305 \mathrm{mV}$ overpotentials to reach the current density of 1 (defined as initial overpotential, tangent line of the measured curves to determine the overpotential of materials) and $10 \mathrm{~mA} \cdot \mathrm{cm}^{-2}$. In addition, the $\mathrm{F}-\mathrm{Ni}(\mathrm{OH})_{2}-\mathrm{SR}-200$ electrode displays the ultralow overpotential of $420 \mathrm{mV}$ to obtain a high current density of up to $300 \mathrm{~mA} \cdot \mathrm{cm}^{-2}$, revealing desirable OER catalytic activity at large current density (Fig. 2(b)). To further understand the mechanism for enhanced OER activity, Tafel plots of the samples were measured (Fig. 2(c)), the F-Ni(OH) ${ }_{2}-\mathrm{SR}-200$ displays a low Tafel slope of $201 \mathrm{mV} \cdot \mathrm{dec}^{-1}$, which is much smaller than F-Ni(OH $)_{2}\left(204 \mathrm{mV} \cdot \mathrm{dec}^{-1}\right), \mathrm{Ni}(\mathrm{OH})_{2}$-SR-200 $\left(246 \mathrm{mV} \cdot \mathrm{dec}^{-1}\right)$, and $\mathrm{Ni}(\mathrm{OH})_{2}\left(254 \mathrm{mV} \cdot \mathrm{dec}^{-1}\right)$. To further study the electrode reaction kinetics, electrochemical impedance spectroscopy (EIS) measurements were conducted, as shown in Fig. 2(d). The $\mathrm{F}-\mathrm{Ni}(\mathrm{OH})_{2}$-SR-200 shows the smallest semicircle of $10 \Omega$ in the low-frequency region than the $\mathrm{F}-\mathrm{Ni}(\mathrm{OH})_{2}(20 \Omega)$, $\mathrm{Ni}(\mathrm{OH})_{2}$-SR-200 (15.8 $\Omega$ ), and $\mathrm{Ni}(\mathrm{OH})_{2}(18.1 \Omega)$, indicating its smallest charge-transfer resistance and fast mass transfer kinetics during OER. The relationship between the Tafel slope of $\mathrm{F}-\mathrm{Ni}(\mathrm{OH})_{2}-\mathrm{SR}-200$ and the charge transfer resistance shows that $\mathrm{F}-\mathrm{Ni}(\mathrm{OH})_{2}$-SR-200 has good rapid oxygen evolution kinetics through surface reconstruction. In addition, the mass activity of OER of F-Ni(OH $)_{2}$-SR-200 at an overpotential of $250 \mathrm{mV}$ is $39.3 \mathrm{~A} \cdot \mathrm{mg}^{-1}$, which is 131 times higher than that of $\mathrm{F}-\mathrm{Ni}(\mathrm{OH})_{2}$ catalyst $\left(0.30 \mathrm{~A} \cdot \mathrm{mg}^{-1}\right)$ (Fig. S8 in the ESM). This result shows that (a)
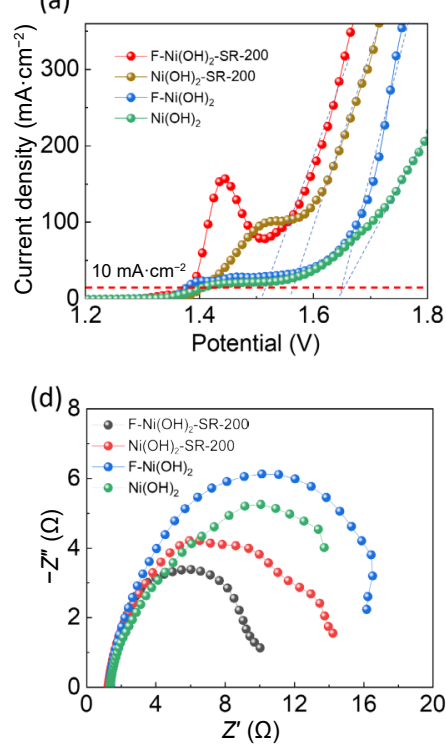

(b)
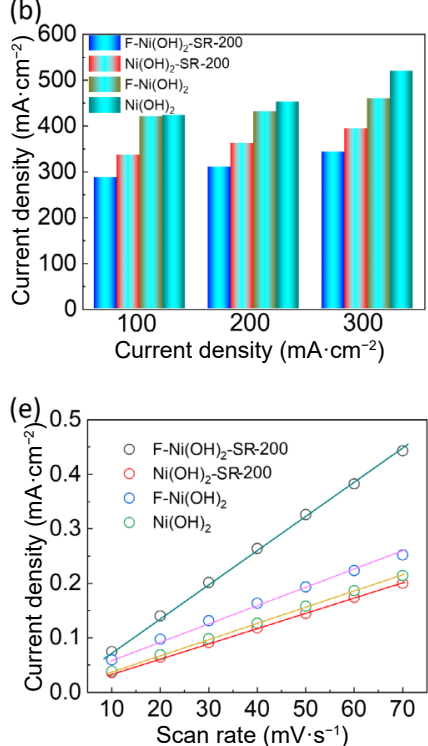

(c)

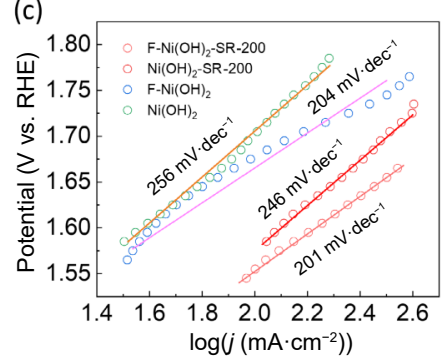

(f)

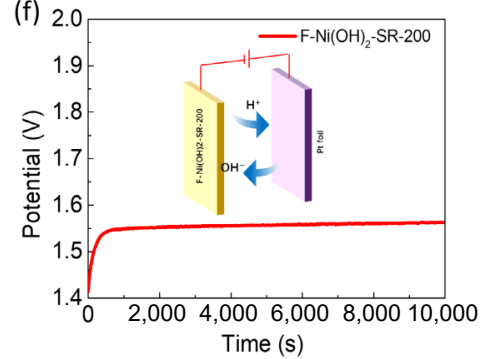

Figure 2 (a) OER polarization curves of $\mathrm{Ni}(\mathrm{OH})_{2}, \mathrm{~F}-\mathrm{Ni}(\mathrm{OH})_{2}, \mathrm{Ni}(\mathrm{OH})_{2}$-SR-200, and $\mathrm{F}-\mathrm{Ni}(\mathrm{OH})_{2}-\mathrm{SR}-200$ samples in $1 \mathrm{M} \mathrm{KOH}$. (b) Comparison of overpotential of $\mathrm{Ni}(\mathrm{OH})_{2}, \mathrm{~F}-\mathrm{Ni}(\mathrm{OH})_{2}, \mathrm{Ni}(\mathrm{OH})_{2}-\mathrm{SR}-200$, and F-Ni(OH $)_{2}-\mathrm{SR}-200$ samples at different current density. (c) Corresponding Tafel plots of $\mathrm{Ni}(\mathrm{OH})_{2}, \mathrm{~F}-\mathrm{Ni}(\mathrm{OH})_{2}, \mathrm{Ni}(\mathrm{OH})_{2}-$ SR-200, and F-Ni(OH) $)_{2}$-SR-200 samples. (d) EIS Nyquist plots of $\mathrm{Ni}(\mathrm{OH})_{2}, \mathrm{~F}-\mathrm{Ni}(\mathrm{OH})_{2}, \mathrm{Ni}(\mathrm{OH})_{2}$-SR-200, and F-Ni(OH) $)_{2}$-SR-200 samples. (e) ECSA of Ni(OH) $\mathrm{Ni}(\mathrm{OH})_{2}, \mathrm{Ni}(\mathrm{OH})_{2}-\mathrm{SR}-200$, and F-Ni(OH $)_{2}$-SR-200 samples. (f) Chronopotentiometry response of F-Ni(OH) ${ }_{2}-\mathrm{SR}-200$. 
the introduction of $\mathrm{F}$ atoms and surface reconstruction on the $\mathrm{F}-\mathrm{Ni}(\mathrm{OH})_{2}-\mathrm{SR}$ can maximize the catalytic activity, thereby significantly reducing the cost of the OER catalyst. To elucidate the reason for the significant increase in OER activity, the electrochemical double-layer capacitance $\left(C_{\mathrm{dl}}\right)$ of the corresponding catalyst was measured by the $\mathrm{CV}$ method to evaluate its electrochemical effective surface area (ECSA) (Fig. S9 in the ESM). Our results show that the $C_{\mathrm{dl}}$ of $\mathrm{F}-\mathrm{Ni}(\mathrm{OH})_{2}-\mathrm{SR}-200$ $\left(6.7 \mathrm{mF} \cdot \mathrm{cm}^{-2}\right)$ is much larger than that of $\mathrm{F}-\mathrm{Ni}(\mathrm{OH})_{2}$, $\mathrm{Ni}(\mathrm{OH})_{2}-\mathrm{SR}-200, \mathrm{Ni}(\mathrm{OH})_{2}$, indicating the newly generated $\mathrm{NiOOH}$ site serves as an accessible active site on F-Ni(OH) $)_{2}$-SR-200 (Fig. 2(e)). The ECSA standardized LSV curve was used to emphasize the intrinsic activity (Fig. S10 in the ESM). The results show that the ECSA normalized current density of $\mathrm{F}-\mathrm{Ni}(\mathrm{OH})_{2}-\mathrm{SR}-200$ is larger than that of $\mathrm{Ni}(\mathrm{OH})_{2}$, indicating the higher OER activity of $\mathrm{F}-\mathrm{Ni}(\mathrm{OH})_{2}$-SR-200 is not only due to the increase of ECSA but also due to the enhancement of intrinsic activity. The electrochemical stability of $\mathrm{F}-\mathrm{Ni}(\mathrm{OH})_{2}-\mathrm{SR}-200$ was also investigated. The chronopotentiometry test indicates that the $\mathrm{F}-\mathrm{Ni}(\mathrm{OH})_{2}-\mathrm{SR}-200$ can maintain the current densities of $10 \mathrm{mV} \cdot \mathrm{cm}^{-2}$ throughout the $10,000 \mathrm{~s}$ with a negligible decrease (Fig. 2(f)), indicating the superior stability in the long-term OER process. This can be attributed to the strong interaction of the $\mathrm{p}-\mathrm{n}$ junction interface. Specifically, the leaching of $F$ ions induces the surface reconstruction and creates $\mathrm{p}-\mathrm{n}$ junction, which leads to a strong interaction of the $\mathrm{p}-\mathrm{n}$ junction interface, enabling high stability of materials structure.

\subsection{Active site identification}

To elucidate the origin of the outstanding OER catalytic performance and the surface reconstruction of $\mathrm{F}-\mathrm{Ni}(\mathrm{OH})_{2}$-SR-200, the dynamic changes in the oxidation state were probed by ex situ analysis. Firstly, XRD patterns were performed to explore the composition of the material, as shown in Fig. S2 in the ESM. The XRD pattern shows four main peaks at $19.3^{\circ}, 33.5^{\circ}, 38.9^{\circ}$, and $59.9^{\circ}$, which correspond to the original structure of $\mathrm{Ni}(\mathrm{OH})_{2}$, indicating that the surface reconstruction of the material does not completely change the phase of the substance. The Raman spectra of $\mathrm{F}-\mathrm{Ni}(\mathrm{OH})_{2}$ shows two peaks located at 249 and $454 \mathrm{~cm}^{-1}$, corresponding to $\mathrm{Ni}(\mathrm{OH})_{2}$ (Fig. 3(a)). However, the peak at $249 \mathrm{~cm}^{-1}$ disappeared and the peak at position $454 \mathrm{~cm}^{-1}$ weakened slightly when increasing the $\mathrm{CV}$ number to 100 times, indicating that the surface structure of $\mathrm{F}-\mathrm{Ni}(\mathrm{OH})_{2}$ undergoes reconstruction during the electrochemical process. After 50 cycles, the peak at $492 \mathrm{~cm}^{-1}$ began to increase, which corresponds to the $\mathrm{NiOOH}$ structure, indicating that the surface reconstruction generated amorphous $\mathrm{NiOOH}$. After cycling up to 150 times, the peak at the position of $454 \mathrm{~cm}^{-1}$ continues to weaken and the peak at the position of $249 \mathrm{~cm}^{-1}$ completely disappears, which indicates that $\mathrm{Ni}(\mathrm{OH})_{2}$ is only partially converted to $\mathrm{NiOOH}$, which forms the $\mathrm{Ni}(\mathrm{OH})_{2} / \mathrm{NiOOH}$ interface structure. Then we performed an ex situ XPS test, the results showed that the content of F ion gradually decreased with increasing $\mathrm{CV}$ times, indicating leaching of $\mathrm{F}$ ions occurred during the whole electrochemical process (Fig. 3(b)). From the Ni 2p XPS spectrum in Fig. 3(c), it is found that the Ni $2 \mathrm{p}$ peak first shifts positively when the CV cycled from 0 to 100 , and then the Ni 2 p peak starts to shift negatively after $100 \mathrm{CV}$. This is because the leaching of $\mathrm{F}$ ion enables $\mathrm{Ni}$ to form unsaturated coordination bonds in $0-100 \mathrm{CV}$ treatment, which reduces surface formation energy and promotes surface reconstruction to form amorphous $\mathrm{NiOOH}$. However, after the surface reconstruction is finished, the $\mathrm{F}-\mathrm{NiOOH}$ generated on the surface continues to leach $\mathrm{F}$ ions under the drive of the electrochemical process due to the break of $\mathrm{F}-\mathrm{Ni}$ bond as
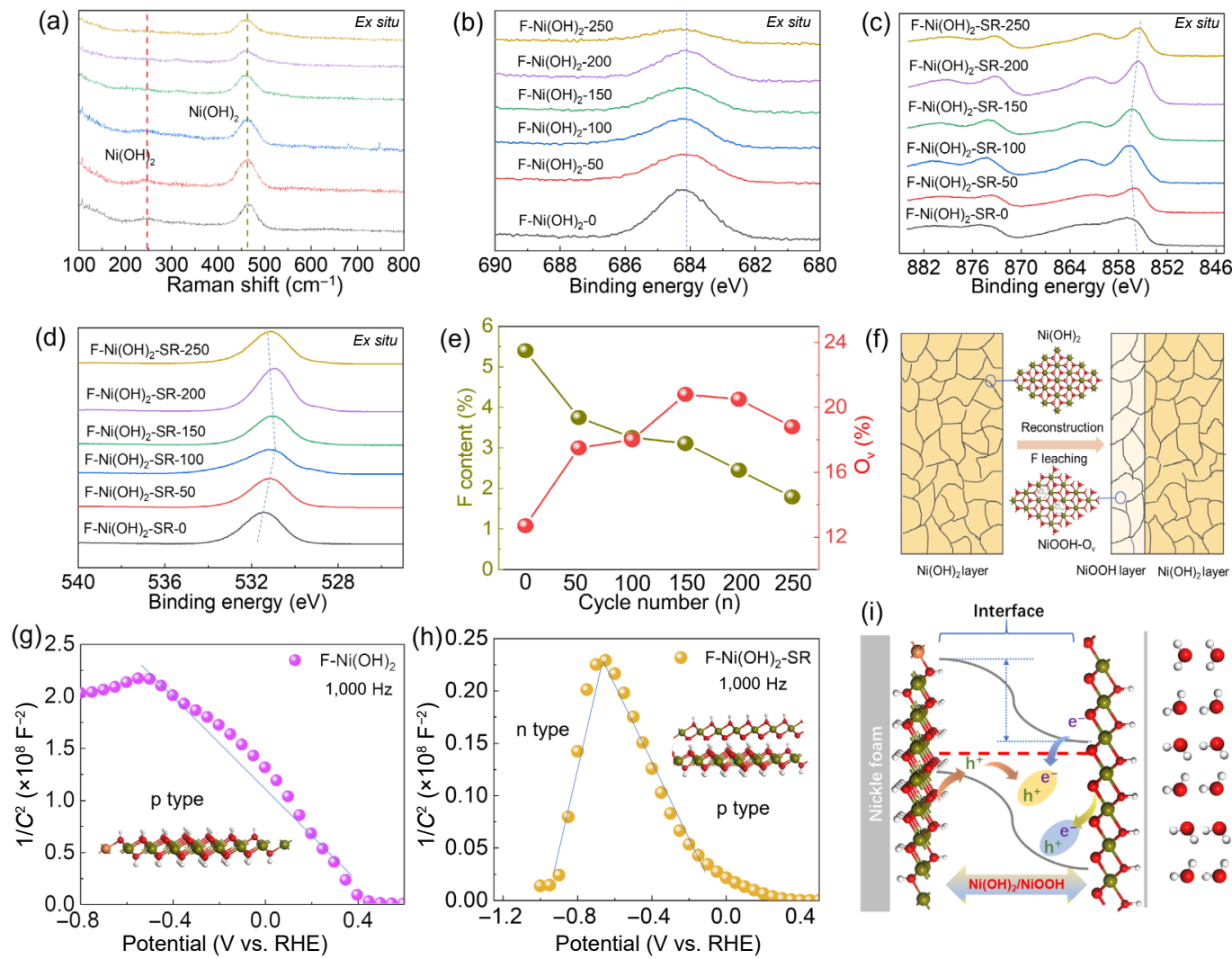

Figure 3 (a) Raman spectra of F-Ni(OH) $)_{2}$ at different CV treatment. Ex situ XPS spectra of (b) F 1s, (c) Ni 2p, and (d) O 1s of F-Ni(OH) $)_{2}$ at different CV treatment. (e) The percentage of $\mathrm{F}$ and $\mathrm{O}_{\mathrm{v}}$ of $\mathrm{F}-\mathrm{Ni}(\mathrm{OH})_{2}$ at different $\mathrm{CV}$ treatment. (f) Schematics of the compositions of F-Ni(OH) $)_{2}$ before and after $\mathrm{CV}$ treatment. Mott-Schottky plots of $(\mathrm{g}) \mathrm{F}-\mathrm{Ni}(\mathrm{OH})_{2}$ and $(\mathrm{h}) \mathrm{F}-\mathrm{Ni}(\mathrm{OH})_{2}$-SR. (i) Proposed mechanism for electrocatalyzing OER in F-NiOOH/F-Ni(OH) 2 p-n junction under the condition of applying enough potential via the external circuit. 
indicated by the negative shift of the Ni $2 \mathrm{p}$ peak. This is also a process of $\mathrm{F}$ ion content optimization, which is beneficial to maximize the electrochemical activity of the material. A similar phenomenon was observed from the $\mathrm{O} 1 \mathrm{~s}$ spectrum, as shown in Fig. 3(d). The O 1s peak first shifts negatively, and then positively, corresponding to the process of $\mathrm{F}$ leaching and $\mathrm{F}$ ion optimization, respectively. This further demonstrates surface reconstruction and $\mathrm{F}$ ion content optimization due to $\mathrm{F}$ ion leaching during the electrochemical treatment. Besides, the fitting results of the $\mathrm{O}$ 1s spectrum showed that the electrochemical reconstruction process was accompanied by the generation of oxygen vacancies, and the presence of oxygen vacancies further enhanced the electrochemical activity of the material. Figure 3(e) shows the change of $\mathrm{F}$ content and the correlation between the content of oxygen vacancies and the number of CVs. With the increase of the number of $\mathrm{CVs}$, the leaching content of $\mathrm{F}$ ions gradually increased, and the effect of electrochemistry makes the oxygen vacancies far higher than the original material. This is because the weak Ni-F bonds easily break down under the continuous potential (1.25-1.65 V), which promotes unsaturated coordination of $\mathrm{Ni}$ atoms, thereby generating more defects. We use the schematic diagram of Fig. 3(f) to illustrate this process. The electrochemical process promotes the leaching of $\mathrm{F}$ ions, and the original $\mathrm{F}-\mathrm{Ni}(\mathrm{OH})_{2}$ undergoes surface reconstruction to form a layer of amorphous $\mathrm{F}-\mathrm{NiOOH}$ on the surface, accompanied by oxygen vacancies.

\subsection{P-n junction and space-charge effect}

As the change of electron density of atoms around the interface will greatly affect the absorption and charge transfer of target ions in the catalytic process [48-52], we explore the charge distribution at the interaction between $\mathrm{F}-\mathrm{NiOOH}$ and $\mathrm{F}-\mathrm{Ni}(\mathrm{OH})_{2}$ using the Mott-Schottky (M-S) p-n junction model. It is known that the formation of a semiconductor junction can reach the non-thermal equilibrium, especially the formation of two opposite charged areas, and a strong internal field is formed at the interface, which can change the electron density of atoms around the interface [48-50]. Besides, the charged surface will greatly affect the absorption and charge transfer of target ions in the catalytic process $[51,52]$. As shown in Figs. 3(g) and 3(h), M-S diagram shows that the original $\mathrm{F}-\mathrm{Ni}(\mathrm{OH})_{2}$ has a negative slope, indicating typical p-type semiconductor of $\mathrm{F}-\mathrm{Ni}(\mathrm{OH})_{2}$ [53-55]. However, the $\mathrm{F}-\mathrm{Ni}(\mathrm{OH})_{2}$-SR-200 has both positive and negative slopes after electrochemical CV treatment, indicating F-Ni(OH) $)_{2}$-SR-200 exhibits both p-type and n-type semiconductor properties [48]. Therefore, the electrochemical process promotes the formation of a heterogeneous structure and the space charge region at the interface of $\mathrm{F}-\mathrm{NiOOH} / \mathrm{F}-\mathrm{Ni}(\mathrm{OH})_{2}$, inducing the space-charge effect (Fig. 3(i)). In this case, the active center with a positive current could be established on the surface of $\mathrm{F}-\mathrm{NiOOH}$, which is helpful to accelerate the transfer of electrons derived from $\mathrm{OH}^{-}$in an alkaline electrolyte to the valence band (VB) of F-NiOOH [48]. Then, the $\mathrm{OH}^{-}$derived electrons are compounded between the holes of $\mathrm{VB}$ of $\mathrm{F}-\mathrm{NiOOH}$, while the excess electrons at conduction band $(\mathrm{CB})$ of $\mathrm{NiOOH}$ are recovered and maintained charge balance by recombination with holes at $\mathrm{VB}$ of $\mathrm{F}-\mathrm{NiOOH}$ [48]. Furthermore, VB with charge imbalance $\mathrm{F}-\mathrm{Ni}(\mathrm{OH})_{2}$ is compensated by applying enough potential through external circuits [48]. As a result, the F-Ni(OH $)_{2}-\mathrm{SR}-200$ exhibits high catalytic activity for OER.

\subsection{DFT calculations}

To gain insights into the surface reconstruction and the improved OER performance, we performed the DFT calculations. Due to the strong electronegativity of $\mathrm{F}$ and the relatively larger atomic size difference between $\mathrm{F}-\mathrm{Ni}$ compared to that of $\mathrm{O}-\mathrm{Ni}$. It is easy for $\mathrm{F}$ to dissociate from the solid phase during the electrochemical activation process, resulting in a large number of vacancies. Specifically, the Ni-F bonds are electrochemically activated by absorbing hydroxyl $\left(\mathrm{OH}^{-}\right)$from the electrolyte and then converted to the highly active $\mathrm{NiOOH}$ species with the leaching of $\mathrm{F}^{-}$. Then, we used the formation energy $\left(E_{\mathrm{f} \text {,vac }}\right)$ of F-vacancy, O-vacancy and $\mathrm{Ni}$-vacancy of $\mathrm{F}-\mathrm{Ni}(\mathrm{OH})_{2}$ to evaluate their thermodynamic stability (Fig. 4(a)). The $E_{\mathrm{f} \text {,vac }}$ value of F-vacancy is calculated to be $-5.87 \mathrm{eV}$, which is lower than O-vacancy $(-1.37 \mathrm{eV})$ and $\mathrm{Ni}$-vacancy $(-2.62 \mathrm{eV})$, indicating that $\mathrm{F}$ atoms are easily leached from $\mathrm{F}-\mathrm{Ni}(\mathrm{OH})_{2}$ and further accelerates surface reconstruction. Therefore, the surface of the $\mathrm{F}-\mathrm{Ni}(\mathrm{OH})_{2}$ is reconstructed into the $\mathrm{NiOOH}$ structures, which is considered to be the true active sites based on the experimental observations.

The correlation between the surface reconstructions and performance of OER is further examined by DFT. The surface models of $\mathrm{F}-\mathrm{Ni}(\mathrm{OH})_{2}$ and $\mathrm{F}-\mathrm{Ni}(\mathrm{OH})_{2}-\mathrm{SR}$, representing the structure before and after surface reconstruction under electrochemical action were created. Three adsorbed intermediates $\left({ }^{\star} \mathrm{OH},{ }^{\star} \mathrm{O}\right.$ and $\left.{ }^{\star} \mathrm{OOH}\right)$ are generated in the OER process with the four-step mechanism, as shown in Fig. S11 in the ESM. The adsorption behaviors of essential intermediates (including ${ }^{\star} \mathrm{OH}$, ${ }^{\star} \mathrm{O}$, and ${ }^{\star} \mathrm{OOH}$ ) during the OER process were investigated on the surface, implying that $\mathrm{Ni}$ sites were stable in the adsorption of OER intermediates. The Gibbs free energy $(\Delta G)$ diagram in Fig. 4(b) shows that after the surface reconstruction occurs, the heterostructure reduces the $\Delta G$ value by about $0.26 \mathrm{eV}$ at the $\mathrm{Ni}$ sites from the ${ }^{\star} \mathrm{OOH}$ intermediate to form $\mathrm{O}_{2}$. This indicates that the heterostructure in the catalyst triggers the electronic region effect, which makes ${ }^{\star} \mathrm{OOH}$ adsorption weaker and promotes the catalyst surface to release $\mathrm{O}_{2}$.

Given the high dependency of conductivity on the band gap, band gaps are a major factor in the assessment of electrocatalyst. The electronic band structures, total and local density of states (TDOS and LDOS) are shown in Figs. S12-S14 in the ESM. A considerably large band gap of $2.0 \mathrm{eV}$ of pure $\mathrm{F}-\mathrm{Ni}(\mathrm{OH})_{2}$ demonstrates its semiconductor characteristics with low electrical conductivity (Fig. S12 in the ESM). While F-NiOOH shows half-metal performance with nearly $0.5 \mathrm{eV}$ band gap of spin-down and no band gap of spin-up as shown in Fig. S13 in the ESM. After surface reconstruction, the surface $\mathrm{Ni}$ atoms with the major spin-up components become conductive as evidenced by the electron states found around the Fermi energy level, which verifies that the $\mathrm{F}-\mathrm{Ni}(\mathrm{OH})_{2}$-SR already has a half-metal-like conductivity. Moreover, the formation of $\mathrm{F}-\mathrm{NiOOH} / \mathrm{F}-\mathrm{Ni}(\mathrm{OH})_{2}$ herotestructure further increases the TDOS of $\mathrm{F}-\mathrm{Ni}(\mathrm{OH})_{2}$, suggesting higher conductivity of the $\mathrm{F}-\mathrm{Ni}(\mathrm{OH})_{2}-\mathrm{SR}$, which can benefit their charge transfer capability during electrochemical reactions. The calculations agree well with the electrochemical impedance spectroscopy measurements (Fig. 2(d)), a much lower charge transfer resistance of $\mathrm{F}-\mathrm{Ni}(\mathrm{OH})_{2}$-SR than $\mathrm{F}-\mathrm{Ni}(\mathrm{OH})_{2}$ implies their more favorable charge transport kinetics. Moreover, the density of state (DOS) also indicates that the $\mathrm{p}$ band center of $\mathrm{F}-\mathrm{Ni}(\mathrm{OH})_{2}-\mathrm{SR}(-8.13 \mathrm{eV})$ is much closer to the Fermi level than that of $\mathrm{F}-\mathrm{Ni}(\mathrm{OH})_{2}$ $(-9.96 \mathrm{eV})$ (Figs. 4(c) and 4(d)), which favors a stronger bonding with the OER intermediates (Fig. 4(e)).

To demonstrated the electronic interaction in $\mathrm{F}-\mathrm{Ni}(\mathrm{OH})_{2}-\mathrm{SR}$, the work function profiles were conducted. The work function profiles of $\mathrm{F}-\mathrm{Ni}(\mathrm{OH})_{2}$ and $\mathrm{F}-\mathrm{NiOOH}$ materials are shown in Figs. 4(f) and $4(\mathrm{~g})$, where $E_{\mathrm{F}}$ is the Fermi energy. The work functions of the $\mathrm{F}-\mathrm{Ni}(\mathrm{OH})_{2}$ and $\mathrm{F}-\mathrm{NiOOH}$ surfaces were determined to be 2.48 and $7.53 \mathrm{eV}$, respectively. As the work functions of $\mathrm{F}-\mathrm{Ni}(\mathrm{OH})_{2}$ and $\mathrm{F}-\mathrm{NiOOH}$ surfaces are compared, we can see that the Fermi energy of $\mathrm{F}-\mathrm{Ni}(\mathrm{OH})_{2}$ is lower than that of F-NiOOH. Since F-Ni(OH $)_{2}$ and F-NiOOH have different Fermi energies, electrons will flow from $\mathrm{F}-\mathrm{Ni}(\mathrm{OH})_{2}$ to $\mathrm{F}-\mathrm{NiOOH}$ until all 

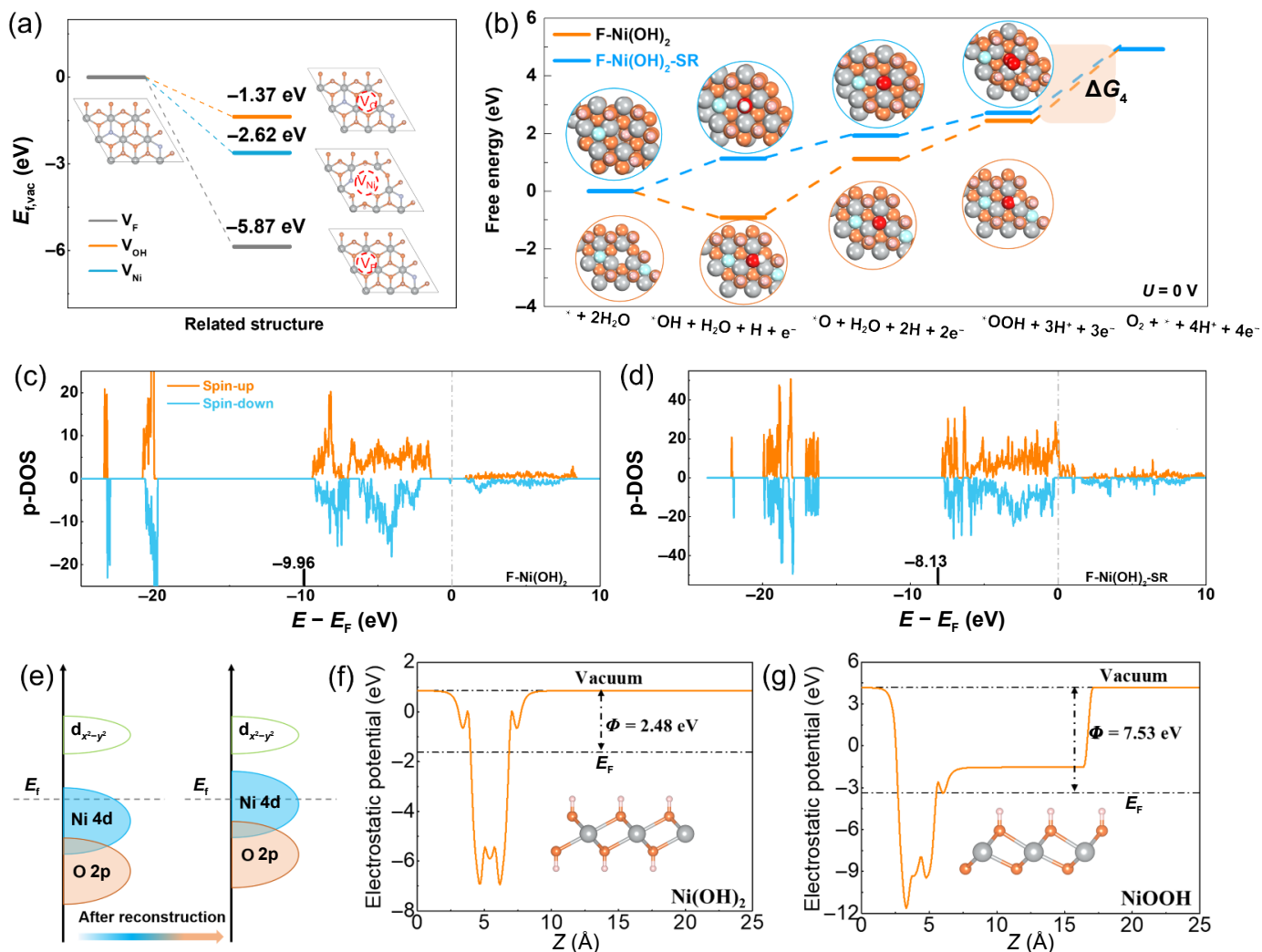

Figure 4 (a) Vacancy formation energies $\left(E_{\mathrm{f} \text { vac }}\right)$ of $\mathrm{F}, \mathrm{O}, \mathrm{Ni}$ atom for $\mathrm{F}-\mathrm{Ni}(\mathrm{OH})_{2}$ slab. (b) Gibbs free energy profiles along the reaction pathway. (c) The DOS of F$\mathrm{Ni}(\mathrm{OH})_{2}$ and $\mathrm{F}-\mathrm{Ni}(\mathrm{OH})_{2}-\mathrm{SR}$. (d) p-band of $\mathrm{O}$ atoms related to OER. (e) Schematic of the orbital changes in metal and nonmetal elements. (f) Work function profiles of F-Ni(OH $)_{2}$ and F-Ni(OH $)_{2}-\mathrm{SR}$. (h) Differential charge density of F-Ni(OH $)_{2}-\mathrm{SR}$.

Fermi energies reach the same level. The charge density difference was measured to further explain the electronic interaction and directional interfacial electron transport, as seen in Fig. S15 in the ESM. Results indicate that the electron density of $\mathrm{F}-\mathrm{Ni}(\mathrm{OH})_{2}$ decreases and the majority of the electrons surrounded on the surface of $\mathrm{F}-\mathrm{NiOOH}$, meaning electrons transfer from $\mathrm{F}-\mathrm{Ni}(\mathrm{OH})_{2}$ to $\mathrm{F}-\mathrm{NiOOH}$ materials. The charge transfer from the $\mathrm{F}-\mathrm{Ni}(\mathrm{OH})_{2}$ to $\mathrm{F}-\mathrm{NiOOH}$ might lead to effective molecule activation which in turn can promote the desorption of $\mathrm{O}_{2}$ at the last step.

\section{Conclusions}

In conclusion, we adopt a facile approach to promote surface reconstruction on $\mathrm{Ni}(\mathrm{OH})_{2}$ and boost its OER activity by incorporating $\mathrm{F}$ anions. The $\mathrm{F}$ anions with the strongest electronegativity trend on forming weak $\mathrm{Ni}-\mathrm{F}$ bonds and achieve stronger ionicity, which is in favor of surface reconstruction of catalytic active species. During the electrochemical process, a amount of the $\mathrm{F}$ ions were leached and induced the original surface layer transformed into a mesoporous and amorphous $\mathrm{F}-\mathrm{NiOOH}$ layer. This self-reconstructed $\mathrm{F}-\mathrm{NiOOH}$ promotes a space-charge effect on the $\mathrm{F}-\mathrm{NiOOH} / \mathrm{F}-\mathrm{Ni}(\mathrm{OH})_{2}$ p-n junction interface. The generated $\mathrm{p}-\mathrm{n}$ junction at the space-charge region can reach a thermal equilibrium state and the strong built-in field at the interface, which is able to change the electron densities of atoms around the interfaces. Besides, the charged surfaces would have a great effect on the absorption of targeted ions and the charge-transfer process during catalysis. This work opens up an entirely new possibility to purposefully regulate the electronic structure of active sites and promote their catalytic activities.

\section{Acknowledgements}

This work was funded by the Science and Technology Development Fund, Macau SAR (Nos. 0191/2017/A3, 0041/2019/A1, 0046/2019/AFJ, and 0021/2019/AIR), University of Macau (Nos.
MYRG2017-00216-FST and MYRG2018-00192-IAPME), UEA funding, the National Natural Science Foundation of China (Nos. 51773211 and 21961160700), the Beijing Municipal Science \& Technology Commission, the IBS (IBS-R019-D1), and the State Key Laboratory of Organic-Inorganic Composites (OIC) (No. 202101002). The DFT calculations were performed at High Performance Computing Cluster (HPCC) of Information and Communication Technology Office (ICTO) at University of Macau.

Electronic Supplementary Material: Supplementary material (the additional real photo, XRD, SEM, TEM, HRTEM, EDS, CV, LSV, and DFT) is available in the online version of this article at https://doi.org/10.1007/s12274-021-3917-7.

Open Access This article is licensed under a Creative Commons Attribution 4.0 International License, which permits use, sharing, adaptation, distribution and reproduction in any medium or format, as long as you give appropriate credit to the original author(s) and the source, provide a link to the Creative Commons licence, and indicate if changes were made.

The images or other third party material in this article are included in the article's Creative Commons licence, unless indicated otherwise in a credit line to the material. If material is not included in the article's Creative Commons licence and your intended use is not permitted by statutory regulation or exceeds the permitted use, you will need to obtain permission directly from the copyright holder.

To view a copy of this licence, visit http://creativecommons. org/licenses/by/4.0/.

\section{References}

[1] Xu, H. B.; Fei, B.; Cai, G. H.; Ha, Y.; Liu, J.; Jia, H. X.; Zhang, J. C.; Liu, M.; Wu, R. B. Boronization-induced ultrathin 2D nanosheets 
with abundant crystalline-amorphous phase boundary supported on nickel foam toward efficient water splitting. Adv. Energy Mater. 2020, 10, 1902714.

[2] Wang, X. P.; Wu, H. J.; Xi, S. B.; Lee, W. S. V.; Zhang, J.; Wu, Z. H.; Wang, J. O.; Hu, T. D.; Liu, L. M.; Han, Y. et al. Strain stabilized nickel hydroxide nanoribbons for efficient water splitting. Energy Environ. Sci. 2020, 13, 229-237.

[3] Li, Y. J.; Sun, Y. J.; Qin, Y. N.; Zhang, W. Y.; Wang, L.; Luo, M. C.; Yang, H.; Guo, S. J. Recent advances on water-splitting electrocatalysis mediated by noble-metal-based nanostructured materials. Adv. Energy Mater. 2020, 10, 1903120.

[4] Tang, W. K.; Liu, X. F.; Li, Y.; Pu, Y. H.; Lu, Y.; Song, Z. M.; Wang, Q.; Yu, R. H.; Shui, J. L. Boosting electrocatalytic water splitting via metal-metalloid combined modulation in quaternary NiFe-P-B amorphous compound. Nano Res. 2020, 13, 447-454.

[5] Wang, Y.; Zheng, X. B.; Wang, D. S. Design concept for electrocatalysts. Nano Res., in press, DOI: 10.1007/s12274-021-37940 .

[6] Shi, Q. R.; Zhu, C. Z.; Du, D.; Lin, Y. H. Robust noble metal-based electrocatalysts for oxygen evolution reaction. Chem. Soc. Rev. 2019, 48, 3181-3192.

[7] Xiao, Z. H.; Huang, Y. C.; Dong, C. L.; Xie, C.; Liu, Z. J.; Du, S. Q.; Chen, W.; Yan, D. F.; Tao, L.; Shu, Z. W. et al. Operando identification of the dynamic behavior of oxygen vacancy-rich $\mathrm{Co}_{3} \mathrm{O}_{4}$ for oxygen evolution reaction. J. Am. Chem. Soc. 2020, 142, 12087-12095

[8] Bai, L. C.; Hsu, C. S.; Alexander, D. T. L.; Chen, H. M.; Hu, X. L. A cobalt-iron double-atom catalyst for the oxygen evolution reaction. J. Am. Chem. Soc. 2019, 141, 14190-14199.

[9] Zhou, D. J.; Cai, Z.; Bi, Y. M.; Tian, W. L.; Luo, M.; Zhang, Q.; Zhang, Q.; Xie, Q. X.; Wang, J. D.; Li, Y. P. et al. Effects of redoxactive interlayer anions on the oxygen evolution reactivity of NiFelayered double hydroxide nanosheets. Nano Res. 2018, 11, 1358-1368.

[10] Zagalskaya, A.; Alexandrov, V. Role of defects in the interplay between adsorbate evolving and lattice oxygen mechanisms of the oxygen evolution reaction in $\mathrm{RuO}_{2}$ and $\mathrm{IrO}_{2}$. ACS Catal. 2020, 10, 3650-3657.

[11] Li, S.; Xi, C.; Jin, Y. Z.; Wu, D. Y.; Wang, J. Q.; Liu, T.; Wang, H. B.; Dong, C. K.; Liu, H.; Kulinich, S. A. et al. Ir-O-V catalytic group in Ir-doped $\mathrm{NiV}(\mathrm{OH})_{2}$ for overall water splitting. ACS Energy Lett. 2019, 4, 1823-1829.

[12] Yeo, B. S. Oxygen evolution by stabilized single Ru atoms. Nat. Catal. 2019, 2, 284-285.

[13] Zhu, R. M.; Zhang, Y.; Ding, J. W.; Pang, H. Thermo-induced nanocomposites with improved catalytic efficiency for oxygen evolution. Sci. China Mater. 2021, 64, 1556-1562.

[14] Anantharaj, S.; Kundu, S.; Noda, S. "The Fe effect": A review unveiling the critical roles of $\mathrm{Fe}$ in enhancing OER activity of $\mathrm{Ni}$ and Co based catalysts. Nano Energy 2021, 80, 105514

[15] Li, X.; Kou, Z. K.; Xi, S. B.; Zang, W. J.; Yang, T.; Zhang, L.; Wang, J. Porous $\mathrm{NiCo}_{2} \mathrm{~S}_{4} / \mathrm{FeOOH}$ nanowire arrays with rich sulfide/hydroxide interfaces enable high OER activity. Nano Energy 2020, 78, 105230.

[16] Sun, K. A.; Zhao, L.; Zeng, L. Y.; Liu, S. J.; Zhu, H. Y.; Li, Y. P.; Chen, Z.; Zhuang, Z. W.; Li, Z. L.; Liu, Z. et al. Reaction environment self-modification on low-coordination $\mathrm{Ni}^{2+}$ octahedra atomic interface for superior electrocatalytic overall water splitting. Nano Res. 2020, 13, 3068-3074.

[17] Yan, M. L.; Mao, K.; Cui, P. X.; Chen, C.; Zhao, J.; Wang, X. Z.; Yang, L. J.; Yang, H.; Wu, Q.; Hu, Z. In situ construction of porous hierarchical $\left(\mathrm{Ni}_{3-\mathrm{r}} \mathrm{Fe}_{x}\right) \mathrm{FeN} / \mathrm{Ni}$ heterojunctions toward efficient electrocatalytic oxygen evolution. Nano Res. 2020, 13, 328-334.

[18] Yang, N.; Tang, C.; Wang, K. Y.; Du, G.; Asiri, A. M.; Sun, X. P. Iron-doped nickel disulfide nanoarray: A highly efficient and stable electrocatalyst for water splitting. Nano Res. 2016, 9, 3346-3354.

[19] Xu, Z. J. Transition metal oxides for water oxidation: All about oxyhydroxides? Sci. China Mater. 2020, 63, 3-7.

[20] Duan, Y.; Sun, S. N.; Sun, Y. M.; Xi, S. B.; Chi, X.; Zhang, Q. H.;
Ren, X.; Wang, J. X.; Ong, S. J. H.; Du, Y. H. et al. Mastering surface reconstruction of metastable spinel oxides for better water oxidation. Adv. Mater. 2019, 31, 1807898.

[21] Li, Y. Y.; Du, X. C.; Huang, J. W.; Wu, C. Y.; Sun, Y. H.; Zou, G. F.; Yang, C. T.; Xiong, J. Recent progress on surface reconstruction of earth-abundant electrocatalysts for water oxidation. Small 2019 , 15,1901980 .

[22] Yang, Z. B.; Liang, X. Self-magnetic-attracted $\mathrm{Ni}_{x} \mathrm{Fe}_{(1-x)} @ \mathrm{Ni}_{x} \mathrm{Fe}_{(1-x)} \mathrm{O}$ nanoparticles on nickel foam as highly active and stable electrocatalysts towards alkaline oxygen evolution reaction. Nano Res. 2020, 13, 461-466.

[23] Wu, T. Z.; Sun, S. N.; Song, J. J.; Xi, S. B.; Du, Y. H.; Chen, B.; Sasangka, W. A.; Liao, H. B.; Gan, C. L.; Scherer, G. G. et al. Ironfacilitated dynamic active-site generation on spinel $\mathrm{CoAl}_{2} \mathrm{O}_{4}$ with self-termination of surface reconstruction for water oxidation. Nat. Cataly. 2019, 2, 763-772.

[24] Wang, L.; Zhou, Q.; Pu, Z. H.; Zhang, Q.; Mu, X. Q.; Jing, H. Y.; Liu, S. L.; Chen, C. Y.; Mu, S. C. Surface reconstruction engineering of cobalt phosphides by $\mathrm{Ru}$ inducement to form hollow $\mathrm{Ru}-\mathrm{RuP}_{x^{-}}$ $\mathrm{Co}_{x} \mathrm{P}$ pre-electrocatalysts with accelerated oxygen evolution reaction. Nano Energy 2018, 53, 270-276.

[25] Huang, J. W.; Li, Y. Y.; Zhang, Y. D.; Rao, G. F.; Wu, C. Y.; Hu, Y.; Wang, X. F.; Lu, R. F.; Li, Y. R.; Xiong, J. Identification of key reversible intermediates in self-reconstructed nickel-based hybrid electrocatalysts for oxygen evolution. Angew. Chem., Int. Ed. 2019, $58,17458-17464$.

[26] Yan, J. Q.; Kong, L. Q.; Ji, Y. J.; White, J.; Li, Y. Y.; Zhang, J.; An, P. F.; Liu, S. Z.; Lee, S. T.; Ma, T. Y. Single atom tungsten doped ultrathin $\alpha-\mathrm{Ni}(\mathrm{OH})_{2}$ for enhanced electrocatalytic water oxidation. Nat. Commun. 2019, 10, 2149.

[27] Kou, T. Y.; Wang, S. W.; Hauser, J. L.; Chen, M. P.; Oliver, S. R. J.; Ye, Y. F.; Guo, J. H.; Li, Y. Ni foam-supported Fe-doped $\beta-\mathrm{Ni}(\mathrm{OH})_{2}$ nanosheets show ultralow overpotential for oxygen evolution reaction. ACS Energy Lett. 2019, 4, 622-628.

[28] Zhao, G. Q.; Li, P.; Cheng, N. Y.; Dou, S. X.; Sun, W. P. An $\mathrm{Ir} / \mathrm{Ni}(\mathrm{OH})_{2}$ heterostructured electrocatalyst for the oxygen evolution reaction: Breaking the scaling relation, stabilizing iridium $(\mathrm{V})$, and beyond. Adv. Mater. 2020, 32, 2000872.

[29] Zhang, Z. B.; Zhu, Y. L.; Zhong, Y. J.; Zhou, W.; Shao, Z. P. Anion doping: A new strategy for developing high-performance perovskitetype cathode materials of solid oxide fuel cells. Adv. Energy Mater. 2017, 7, 1700242.

[30] Chen, P. Z.; Zhou, T. P.; Wang, S. B.; Zhang, N.; Tong, Y.; Ju, H X.; Chu, W. S.; Wu, C. Z.; Xie, Y. Dynamic migration of surface fluorine anions on cobalt-based materials to achieve enhanced oxygen evolution catalysis. Angew. Chem., Int. Ed. 2018, 57, 15471-15475.

[31] Zhang, B. W.; Hu, S. Turning Ni-based hydroxide into an efficient hydrogen evolution electrocatalyst by fluoride incorporation Electrochem. Commun. 2018, 86, 108-112.

[32] Li, R. Q.; Liu, Q.; Zhou, Y. N.; Lu, M. J.; Hou, J. L.; Qu, K. G.; Zhu, Y. C.; Fontaine, O. 3D self-supported porous vanadium-doped nickel nitride nanosheet arrays as efficient bifunctional electrocatalysts for urea electrolysis. J. Mater. Chem. A 2021, 9, 4159-4166.

[33] Shi, P.; Cheng, X. D.; Lyu, S. L. Efficient electrocatalytic oxygen evolution at ultra-high current densities over 3D Fe, N doped $\mathrm{Ni}(\mathrm{OH})_{2}$ nanosheets. Chin. Chem. Lett. 2021, 32, 1210-1214.

[34] Mu, C.; Butenko, D. S.; Odynets, I. V.; Zatovsky, I. V.; Li, J. Z.; Han, W.; Klyui, N. I. $\mathrm{Na}_{4} \mathrm{Ni}_{3} \mathrm{P}_{4} \mathrm{O}_{15}-\mathrm{Ni}(\mathrm{OH})_{2}$ core-shell nanoparticles as hybrid electrocatalysts for the oxygen evolution reaction in alkaline electrolytes. Dalton Trans. 2020, 49, 8226-8237.

[35] Wang, Y. Q.; Tao, S.; Lin, H.; Han, S. B.; Zhong, W. H.; Xie, Y. S.; $\mathrm{Hu}$, J.; Yang, S. H. $\mathrm{NaBH}_{4}$ induces a high ratio of $\mathrm{Ni}^{3+} / \mathrm{Ni}^{2+}$ boosting OER activity of the NiFe LDH electrocatalyst. RSC Adv. 2020, 10 , 33475-33482.

[36] Xu, Q. C.; Chu, M. S.; Liu, M. M.; Zhang, J. H.; Jiang, H.; Li, C. Z. Fluorine-triggered surface reconstruction of $\mathrm{Ni}_{3} \mathrm{~S}_{2}$ electrocatalysts towards enhanced water oxidation. Chem. Eng. J. 2021, 411, 128488.

[37] Li, S. L.; Li, Z. C.; Ma, R. G.; Gao, C. L.; Liu, L. L.; Hu, L. P.; Zhu, J. L.; Sun, T. M.; Tang, Y. F.; Liu, D. M. et al. A glass-ceramic with 
accelerated surface reconstruction toward the efficient oxygen evolution reaction. Angew. Chem., Int. Ed. 2021, 60, 3773-3780.

[38] Ren, X.; Wei, C.; Sun, Y. M.; Liu, X. Z.; Meng, F. Q.; Meng, X. X.; Sun, S. N.; Xi, S. B.; Du, Y. H.; Bi, Z. F. et al. Constructing an adaptive heterojunction as a highly active catalyst for the oxygen evolution reaction. Adv. Mater. 2020, 32, 2001292.

[39] Wang, Y.; Zhu, Y. L.; Zhao, S. L.; She, S. X.; Zhang, F. F.; Chen, Y.; Williams, T.; Gengenbach, T.; Zu, L. H.; Mao, H. Y. et al. Anion etching for accessing rapid and deep self-reconstruction of precatalysts for water oxidation. Matter 2020, 3, 2124-2137.

[40] Sun, Y.; Li, R.; Chen, X. X.; Wu, J.; Xie, Y.; Wang, X.; Ma, K. K.; Wang, L.; Zhang, Z.; Liao, Q. L. et al. A-site management prompts the dynamic reconstructed active phase of perovskite oxide OER catalysts. Adv. Energy Mater. 2021, 11, 2003755.

[41] Xu, C. Y.; Lu, W.; Yan, L.; Ning, J. Q.; Zheng, C. C.; Zhong, Y. J.; Zhang, Z. Y.; Hu, Y. Hierarchical molybdenum-doped cobaltous hydroxide nanotubes assembled by cross-linked porous nanosheets with efficient electronic modulation toward overall water splitting. $J$. Colloid Interface Sci. 2020, 562, 400-408.

[42] Tong, H.; Meng, Q.; Liu, J.; Li, T. T.; Gong, D. X.; Xiao, J. P.; Shen, L. F.; Zhang, T. F.; Bing, D.; Zhang, X. G. Cross-linked $\mathrm{NiCo}_{2} \mathrm{O}_{4}$ nanosheets with low crystallinity and rich oxygen vacancies for asymmetric supercapacitors. J. Alloys Compd. 2020, 822, 153689.

[43] Shinde, N. M.; Raut, S. D.; Ghule, B. G.; Gunturu, K. C.; Pak, J. J.; Mane, R. S. Recasting Ni-foam into $\mathrm{NiF}_{2}$ nanorod arrays via a hydrothermal process for hydrogen evolution reaction application. Dalton Trans. 2021, 50, 6500-6505.

[44] Jiang, X. L.; Tang, M. Y.; Tang, L.; Jiang, N.; Zheng, Q. J.; Xie, F. Y.; Lin, D. M. Hornwort-like hollow porous $\mathrm{MoO}_{3} / \mathrm{NiF}_{2}$ heterogeneous nanowires as high-performance electrocatalysts for efficient water oxidation. Electrochim. Acta 2021, 379, 138146.

[45] Sang, Y.; Cao, X.; Wang, L. X.; Ding, G. F.; Wang, Y. J.; Yu, D. S.; Hao, Y. N.; Li, L. L.; Peng, S. J. Facile synthesis of threedimensional spherical $\mathrm{Ni}(\mathrm{OH})_{2} / \mathrm{NiCo}_{2} \mathrm{O}_{4}$ heterojunctions as efficient bifunctional electrocatalysts for water splitting. Int. J. Hydrogen Energy 2020, 45, 30601-30610.

[46] Hao, J.; Liu, J. W.; Wu, D.; Chen, M. X.; Liang, Y.; Wang, Q.; Wang, L.; Fu, X. Z.; Luo, J. L. In situ facile fabrication of $\mathrm{Ni}(\mathrm{OH})_{2}$ nanosheet arrays for electrocatalytic co-production of formate and hydrogen from methanol in alkaline solution. Appl. Catal. B:Environ. 2021, 281, 119510 .

[47] Liu, H. Q.; Zhao, D. P.; Liu, Y.; Tong, Y. L.; Wu, X.; Shen, G. Z. NiMoCo layered double hydroxides for electrocatalyst and supercapacitor electrode. Sci. China Mater. 2021, 64, 581-591.

[48] He, K.; Tsega, T. T.; Liu, X.; Zai, J. T.; Li, X. H.; Liu, X. J.; Li, W. H.; Ali, N.; Qian, X. F. Utilizing the space-charge region of the FeNi$\mathrm{LDH} / \mathrm{CoP} \mathrm{p}-\mathrm{n}$ junction to promote performance in oxygen evolution electrocatalysis. Angew. Chem. 2019, 131, 12029-12035.

[49] Zhang, K.; Kim, W.; Ma, M.; Shi, X. J.; Park, J. H. Tuning the charge transfer route by $\mathrm{p}-\mathrm{n}$ junction catalysts embedded with $\mathrm{CdS}$ nanorods for simultaneous efficient hydrogen and oxygen evolution. J. Mater. Chem. A 2015, 3, 4803-4810.

[50] Anwer, H.; Park, J. W. Addressing the OER/HER imbalance by a redox transition-induced two-way electron injection in a bifunctional $\mathrm{n}-\mathrm{p}-\mathrm{n}$ electrode for excellent water splitting. J. Mater. Chem. A 2020, 8, 13218-13230.

[51] Wang, G. R.; Li, Y. B.; Xu, L.; Jin, Z. L.; Wang, Y. B. Facile synthesis of difunctional NiV LDH@ZIF-67 p-n junction: Serve as prominent photocatalyst for hydrogen evolution and supercapacitor electrode as well. Renew. Energy 2020, 162, 535-549.

[52] She, H. D.; Yue, P. F.; Huang, J. W.; Wang, L.; Wang, Q. Z. Onestep hydrothermal deposition of $\mathrm{F}$ : $\mathrm{FeOOH}$ onto $\mathrm{BiVO}_{4}$ photoanode for enhanced water oxidation. Chem. Eng. J. 2020, 392, 123703.

[53] Xue, Z. H.; Su, H.; Yu, Q. Y.; Zhang, B.; Wang, H. H.; Li, X. H.; Chen, J. S. Janus Co/CoP nanoparticles as efficient Mott-Schottky electrocatalysts for overall water splitting in wide $\mathrm{pH}$ range. $A d v$. Energy Mater. 2017, 7, 1602355.

[54] Chen, J. Y.; Fan, C.; Hu, X. Y.; Wang, C.; Huang, Z. H.; Fu, G. T.; Lee, J. M.; Tang, Y. W. Hierarchically porous $\mathrm{Co} / \mathrm{Co}_{x} \mathrm{M}_{y}(\mathrm{M}=\mathrm{P}, \mathrm{N})$ as an efficient Mott-Schottky electrocatalyst for oxygen evolution in rechargeable Zn-air batteries. Small 2019, 15, 1901518.

[55] Hou, J. G.; Sun, Y. Q.; Wu, Y. Z.; Cao, S. Y.; Sun, L. C. Promoting active sites in core-shell nanowire array as Mott-Schottky electrocatalysts for efficient and stable overall water splitting. $A d v$. Funct. Mater. 2018, 28, 1704447. 